Provided for non-commercial research and education use. Not for reproduction, distribution or commercial use.

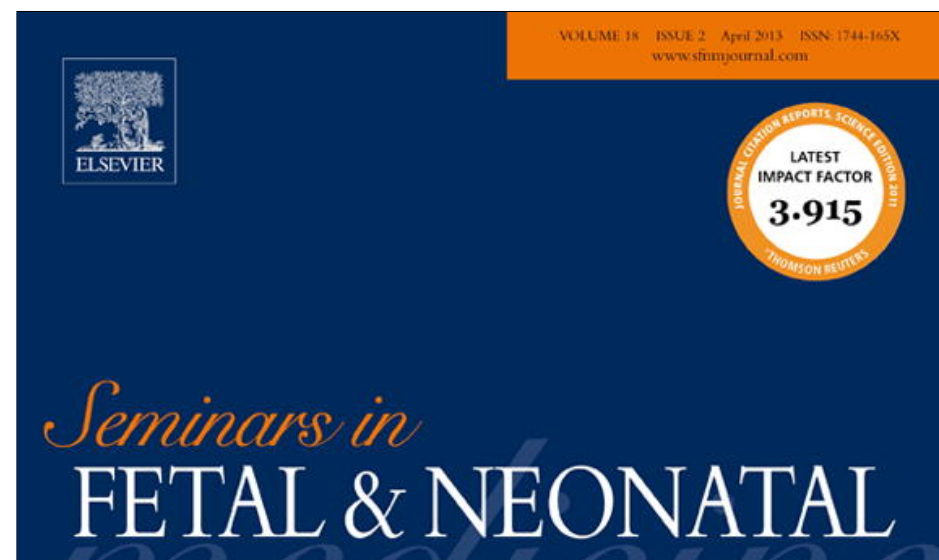

This article appeared in a journal published by Elsevier. The attached copy is furnished to the author for internal non-commercial research and education use, including for instruction at the authors institution and sharing with colleagues.

Other uses, including reproduction and distribution, or selling or licensing copies, or posting to personal, institutional or third party websites are prohibited.

In most cases authors are permitted to post their version of the article (e.g. in Word or Tex form) to their personal website or institutional repository. Authors requiring further information regarding Elsevier's archiving and manuscript policies are encouraged to visit:

http://www.elsevier.com/authorsrights 


\title{
Psychological effects of stillbirth
}

\author{
Joanne Cacciatore* \\ Arizona State University, School of Social Work, 411 N. Central Avenue, 8th Floor, Phoenix, AZ 85004, USA
}

\section{Keywords:}

Death of a baby

Mindfulness

Newborn death

Psychology of perinatal death

Psychosocial care

Stillbirth

\section{S U M M A R Y}

Despite the high prevalence globally, the death of a baby to stillbirth is an often misunderstood and disenfranchised loss. Mothers, fathers, and families struggle to cope with the immediate and long-lasting effects of a baby's death which can last for years and sometimes decades. In addition, providers can be adversely affected by stillbirth, particularly when met with experiential avoidance and a sense of guilt and failure. There is little evidence on intervention efficacy in acute grief following perinatal death; however, there is a growing body of scientific literature on the efficacy of mindfulness-based interventions in treating anxiety, depression, and other biopsychosocial maladies as well as improving patient satisfaction with psychosocial care. This paper explores one such intervention model, ATTEND (attunement, trust, therapeutic touch, egalitarianism, nuance, and death education), as a means to improve psychosocial care during both acute and chronic states of bereavement. Whereas the death of a baby to stillbirth is the ultimate paradox for providers and patients - the convergence of life and death and the fundamental contradiction it represents - with proper care and compassion, families stand a better chance in the face of such indescribable loss and they need not suffer alone.

Published by Elsevier Ltd.

\section{Introduction}

Mourning my child,

I wandered up and down,

Naked, unheeding, streaming hair unkempt,

Lodging in scourings of the streets, and where

The dead lay still, and by the chariot-roads -

So three years long I fared, starving, athirst. ${ }^{1}$

Despite the advancement of thanatological research, stillbirth remains one of the most disenfranchised and misunderstood types of loss. Every day worldwide more than 7300 babies, almost three million during the third trimester annually, are stillborn. ${ }^{2}$ There are few if any more traumatic experiences a woman can endure then giving birth to a baby who has died. The consequences of stillbirth are emotional, cognitive, psychological, social, spiritual, and physiological. $^{2-5}$

Many stillbirths occur at or near full-term to otherwise apparently healthy infants. According to postmortem data, the etiology in about one-half of all stillborn infants is undeterminable. ${ }^{2}$ As such, mothers are often left searching for answers, internalizing feelings

\footnotetext{
* Tel.: +1 6024960073

E-mail address: jcaccia@me.com.
}

of guilt and shame. With nothing else to blame, they often assume the burden of guilt for their baby's death themselves. $2,3,6$

Whereas the etiological factors associated with stillbirth remain elusive for clinicians and researchers, ${ }^{2}$ the psychosocial consequences are even more obscure. Stillbirth is often referred to as the invisible death. ${ }^{6}$ There is, indeed, an implacable quality to stillbirth, a suffocating sense of failure and shame for women. Yet, the effects have a broader reach, often unrecognized, extending into partner relationships, surviving and subsequent children, professional career and workplace colleagues, friendships, and even affecting healthcare providers.

While this paper focuses on the psychological effects of stillbirth on women, families, and providers, it is also crucial to consider the gestalt of the experience and how broader systems influence individual outcomes. For example, mothers experiencing stillbirth are recognized as disenfranchised. Doka ${ }^{7}$ defines disenfranchised grief as the 'grief persons experience when they incur a loss that is not or cannot be openly acknowledged, publicly mourned, or socially supported' (p. 103). For socially validated deaths, there is often community outpouring of sympathy and recognition of the deceased. However, individuals suffering from disenfranchised grief often do so in silence and may feel ashamed of their experiences, adding to the psychological complexity of their losses. Doka $^{8}$ also posits three fundamental considerations in grief: (i) social and psychological variables such as culture; (ii) the developmental context of the relationship to the deceased (for example, the age of 
the mourner and the relationship to the decedent); and (iii) the etiology of the illness that caused the death. The relationship between a woman and her healthcare provider can also affect outcomes.

For example, Lovell found that as soon as physicians discovered that a baby had died, 'there was an abrupt cut off in the identity construction process' and that 'denial of the baby's existence was expressed' both explicitly and implicitly. ${ }^{9}$ In a dramatic instant, there is an 'unraveling of a woman's lived experience and rapid deconstruction of her motherhood' at the hands of the person who was most intimately entrusted with her care for many months. The altered relationship can elicit negative immediate effects and poor long-term psychological outcomes for mothers and families. ${ }^{9}$

\section{Immediate effects}

When framing the experience of stillbirth, it is important to remember that maternal behaviors are not merely a product of emotion and affect. Giving birth, whether the baby is dead or alive, is physiological. Rowe-Murray and Fisher identified three variables salient in mothers diagnosed with postpartum depression, often comorbid with traumatic birth: lack of support, pain, and suboptimal contact with the baby right after birth. ${ }^{10}$

If a live birth can incite trauma symptomatology and adverse psychological outcomes, the consequences of a birth resulting in death would most certainly be far graver. There is no more 'suboptimal first contact' as when the baby has died. ${ }^{10}$ To add to the serious psychological risk, there is significantly less social support offered to the mother, a lack of recognition for the baby as a unique and valued family member, and the process of labor, birth, and postpartum recovery is reported as 'insufferably' more painful. ${ }^{2,11-14}$

During the birth of a baby who died, mothers feel fearful, shocked, numb, and want to 'escape'. They most often expressed the desire for provider sympathy, understanding, and psychoeducation to ease their fears and assuage the immediate effects of their suffering. ${ }^{13}$ Mothers feel appreciative when providers engage in meaningful acts of ritualization with them, often expressing gratitude for microrituals such as taking photographs, holding the baby, and collecting mementos. ${ }^{13,15}$ However, the literature is not devoid of controversy: Whereas some studies demonstrate that rituals, such as holding the stillborn baby, improve long-term outcomes for women, other studies suggest that doing so may increase risk of negative psychiatric sequelae. ${ }^{13,16,17}$

Upon release from the hospital, mothers return home to empty nurseries, dressers filled with newborn clothes and diapers, breasts full with milk for their baby who died, and the anticipation of family and friends met with sorrow and tragedy. The psychosocial and biological stressors in the immediate aftermath of a baby's death can be overwhelming for grieving mothers.

Indeed, to address individual nuances in acute bereavement care, Condon proposes four aspects of stillbirth, differentiating it from other types of bereavement experiences: (i) the uniqueness of the baby who died; (ii) the complexity of maternal attachment to the baby; (iii) the unusual psychobiological climate in which the baby is born and dies; and (iv) cultural influences on the meaning of the loss. ${ }^{18}$

\section{Long-term effects}

Far beyond the acute crisis, the effects of stillbirth reverberate throughout family narratives. Women describe enduring guilt, shame, anger, and both active and passive thoughts of self-harm. ${ }^{12}$ Even three years after stillbirth, bereaved mothers were twice as likely to report anxious symptoms compared with mothers of live- born babies. ${ }^{11}$ Mothers report feelings of disenfranchisement, along with 'social pressure to forget', 'move on', and 'have another baby', often from well-intending friends and family. They report feeling as if they are alone in their mourning, 'no one else missing' the baby who died because their 'interaction with the baby was limited.'12

The long-term effects of perinatal death have been associated with depression, anxiety, obsessive-compulsive behaviors, suicidal ideation, guilt, shame, substance use, marital conflict, and posttraumatic stress and can last for years and sometimes decades. ${ }^{3,6,9,16-20}$ Parents may end up feeling socially isolated, riven by the painful emotions which are often concomitant in perinatal death, particularly absent social support. For example, Barr examined the effects of guilt and shame proneness on parental grief at one month and again at 13 months after the baby's death. While shame proneness influenced grief more significantly at one month post loss, both guilt and shame played a role in predicting the intensity of later grief. Neuroticism, insufficient ego strength, defensiveness, personal inadequacy, and self-criticism predict grief more strongly than demographic, social, and pregnancy and infant variables. ${ }^{21}$ These negative, self-denigrating, moral emotions often coexist with grief but may be more pronounced in perinatal death, particularly since mothers (and sometimes fathers) commonly feel responsible for the death, experience survivor guilt, or even the narcissistic injury of failure to complete an assumed basic biological function. ${ }^{18}$

Both mothers and fathers experience somatic symptoms in the months and years following the death of a baby. Recent research suggests that parental grief poses great health risk: being a bereaved parent has a marked influence on premature mortality that persists for up to 25 years after the child's death. ${ }^{22,23}$ One study conducted in Scotland found a two-fold mortality risk within the first 15 years after the death of a baby. ${ }^{22}$ Another study based on data from the Jerusalem Perinatal Study found that mothers of stillborn infants had increased hazard ratio for premature mortality even when controlling for issues related to maternal health such as pre-eclampsia. The increased risk remained strongly associated with coronary heart disease and renal and circulatory disorders. ${ }^{23}$

\section{Effects on mothers and fathers}

\subsection{Marital relationships}

The death of a child takes a heavy toll on the marital relationship. Parents of stillborn babies face an increased risk of marital dissolution. ${ }^{24}$ Further, they may experience marital disharmony and challenges related to sexuality, communication, and discordant grieving following the loss (J. Cacciatore and L. Umphrey, unpublished study). Mothers who perceive discordant grief are reluctant to open up to their partners, and they report feeling more isolated (J. Cacciatore and L. Umphrey, unpublished study). ${ }^{19}$ Fathers often turn toward sexual intercourse with their partners as a means through which to gain comfort. Yet some mothers report that sexual contact, as a means through which she may experience physical pleasure, feels like a betrayal to the child who died (J. Cacciatore and L. Umphrey, unpublished study).

Additionally, bereaved fathers often report social pressure to 'be strong' and be the 'protector' and are often overlooked in the grief experience (J. Cacciatore and L. Umphrey, unpublished study). ${ }^{6,19}$ Vance et al. suggest that this may be, in part, because mothers tend to express emotional distress more openly and for longer periods of time than fathers, approximately two to three years post loss for mothers versus eight months for fathers. ${ }^{20}$

Whereas relational satisfaction has been consistently linked to better mental health outcomes for bereaved mothers, high levels of distress in one or both partners can result in lower ratings of 
marital satisfaction, thus dyadic harmony is not insulatory against grief responses for either gender. There is a reciprocity in both marital satisfaction and emotional distress; poor marital satisfaction can lead to later distress and serious distress can lead to marital dissatisfaction (J. Cacciatore and L. Umphrey, unpublished study). ${ }^{19}$

However, not all dyads struggle in the aftermath of stillbirth. Those who perceive their partners as caring and engaged also perceived the relationship as closer and more intimate (J. Cacciatore and L. Umphrey, unpublished study). ${ }^{19}$ Parents in these types of relationships often report a feeling of increased cohesion, satisfaction, and intimacy despite the interminable nature of their grief.

\subsection{Meaning-making}

Potentially, suffering may be protracted, in part, due to the unexpected and anachronistic nature of the loss. A child's death is perceived as 'senseless', and parental roles in its wake are forcibly transformed in a distinctly unwelcome direction. Meanwhile, the search for meaning becomes a nigh-unbearable task. ${ }^{25}$ The process of meaning-making, a process that contributes to bereavement adaptation, includes finding even a modicum of import from the experience. Parents who reported the discovery of meaning in their child's death, even though they were not actively seeking such meaning, reported less mental distress, greater marital satisfaction, ongoing bonds with the child who died, and better physical health outcomes. ${ }^{12,15,25}$ Parents who reported no meaning in their child's death were four times more likely to report symptoms of prolonged, intensive grief. ${ }^{25}$ Studies suggest that at about five years after the loss, meaning shifted for parents, and their child's death held new relevance. They reported perspective shifts which incited a reordering of priorities, existential insights into the meaning of life, altruism and helping others who had experienced loss, enhanced appreciation for life, and a deepening of trust in themselves. ${ }^{12,25}$

\subsection{Psychosocial support}

Psychosocial support by medical providers can significantly improve a family's outcomes after stillbirth. However, studies suggest that providers may be avoidant, feel helpless and guilty, or they may experience a sense of failure when a baby dies. These emotional states may result in the perception that the provider lacks care or concern for the family. ${ }^{14,26}$ Providers can mitigate some of the long-term negative outcomes for parents by spending extra time with grieving parents, facilitating the gathering of muchneeded mementos, facilitating bonding, validating their emotional expressions, and enabling the family to make informed decisions about their baby's body. This will allow families to manage postmortem rituals in a way that is consistent with their cultural beliefs and values. ${ }^{14-16,26}$

ATTEND is a mindfulness-based bereavement care (MBC) model which provides a framework within which medical and mental health providers can offer bereaved parents culturally appropriate and compassionate psychosocial care. ${ }^{26}$ The acronym stands for attunement, trust, therapeutic touch, egalitarianism, nuance, and death education and encompasses three aspects in psychosocial care: self, other, and self-other. This model emphasizes highly personalized care that is mindful, humble, and nuanced. To be attuned with a family means to be fully present and deeply selfaware. It is vital that healthcare providers maintain awareness of their own feelings toward the death of a baby. ${ }^{14,26}$ Being an attuned provider will improve sensitivity toward the grieving family. Trust is established through honest and open communication and a willingness to witness their suffering. Appropriately timed therapeutic touch has been shown to reduce distress and improve rapport. Egalitarian providers evince humility in their interactions with bereaved parents. This enables parents to feel a greater sense of control over their experiences, less reluctance to express their wishes, concerns, or fears, particularly around rituals such as seeing, holding, or bathing the baby. Nuanced caregiving precludes the use of rigid checklists or protocols in psychosocial caregiving. Rather, each individual, family, and circumstance is seen as unique, worthy of openness, curiosity, and compassion. Finally, death education is binary. First, psychoeducation from the provider to the patient is of utmost importance in helping families feel in control of their experience. This includes providing birthing options, open and honest discussion about fears the family may have, answering questions regarding grief, and addressing any concerns which may arise so they are fully informed each step along the way. Educating bereaved parents is vital and may help to alleviate irremediable decisions which parents later may regret such as not seeing or holding the baby and not taking memorial photographs (called 'memento mori' photographing). Resource provision is also a function of psychoeducation. Parents often want direct, clear, and honest medical information. Second, continuing education in death and trauma studies for providers helps them feel more prepared to deal with the death of a baby. This can alleviate experiential avoidance, a factor salient when measuring vicarious trauma, and an unwelcomed attribute reported by patients who report transgressions in psychosocial care Figures 1 and $2 .^{14}$

\subsection{Interventions}

There are no randomized controlled trials on the efficacy of early interventions with mothers who have experienced stillbirth. However, in general, positive interpersonal relationships and strong social support are two types of interventions which are negatively correlated with grief intensity. ${ }^{27}$ This suggests that, while not the sole variable influencing psychological outcomes for grieving mothers and fathers, psychosocial care and support can reduce the risk of negative affect. Lavender and Walkinshaw conducted a randomized controlled trial (RCT) on women who had experienced traumatic birth and found that supportive counseling, understanding, and explanation - as a formal intervention provided psychological benefit to women. ${ }^{28}$ Although not conducted specifically on mothers who had experienced the stillbirth of a baby, another RCT demonstrated similar outcomes following traumatic births: a counseling intervention that allowed mothers to express their emotions and retell their stories, led by their

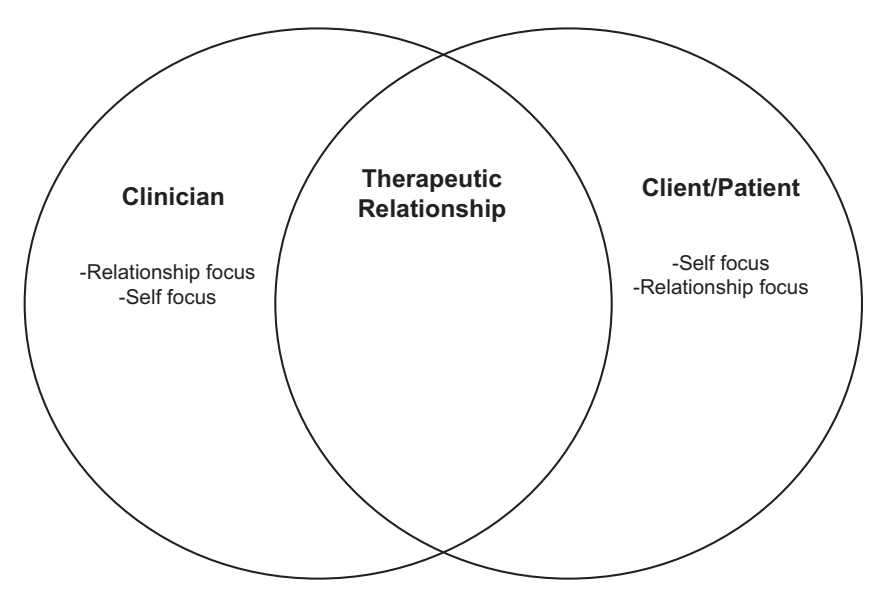

Figure 1. Tripartite framework for ATTEND (attunement, trust, therapeutic touch, egalitarianism, nuance, and death education). 


\section{ATTEND: Mindfulness-based Bereavement Care (MBC) Model}

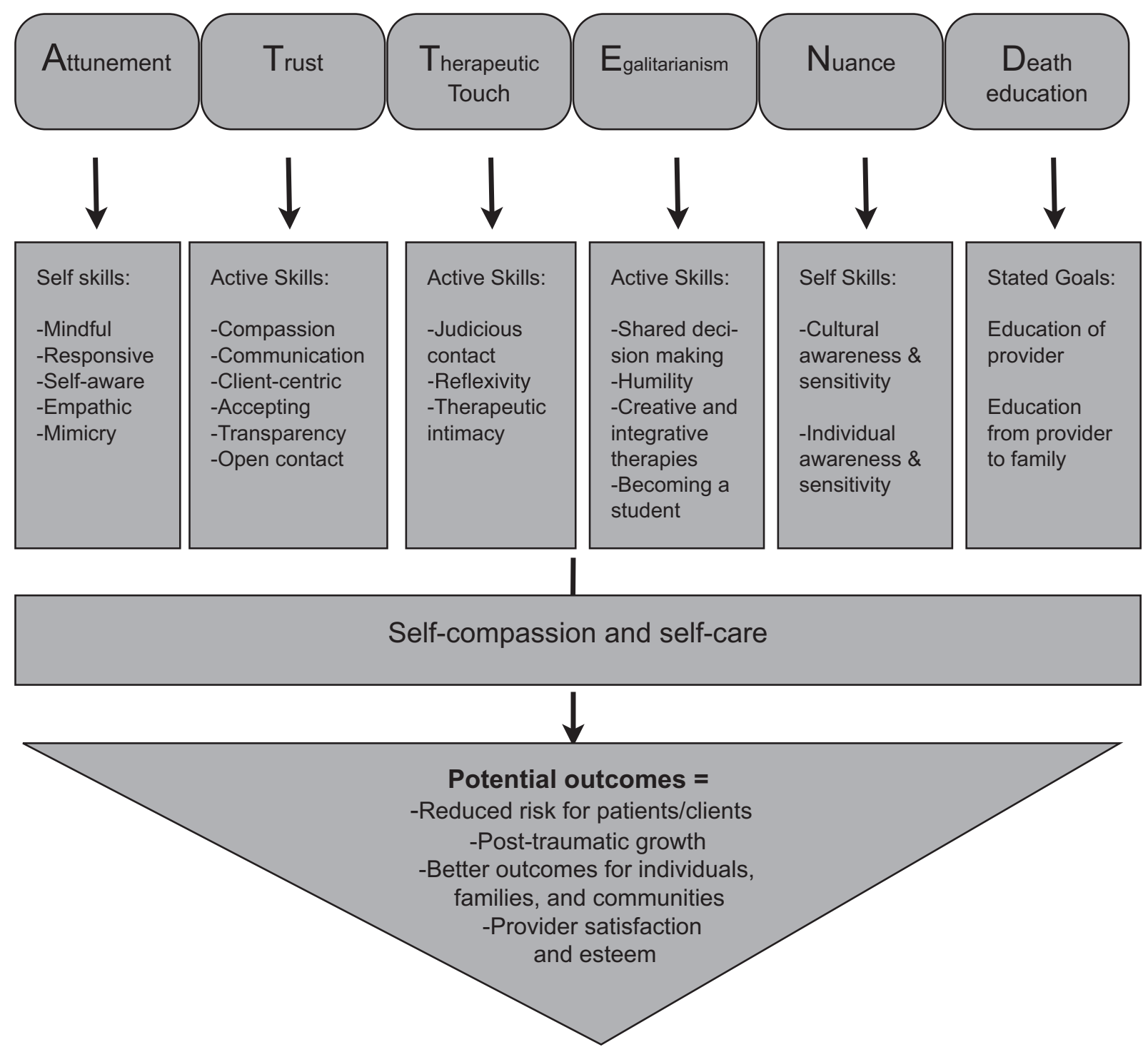

Figure 2. ATTEND mindfulness-based bereavement care model.

midwives, diminished reported symptoms of depression, selfblame, and trauma. ${ }^{29}$

\section{Effects on siblings}

\subsection{Surviving children}

The loss of a baby to stillbirth can have intergenerational effects. Maternal distress can affect the family constellation for surviving children as well as carrying over into a subsequent pregnancy. The additional burden on suffering parents of taking care of surviving children can be overwhelmingly stressful and confusing. Fletcher notes that there are complex challenges facing families with surviving children due to the unnaturalness of the baby's death, parents' perceived failure to protect the child who died, the reorganization of the family and individual roles within the system, and troubled communication. ${ }^{30}$

Siblings have been poised and psychologically prepared to make a space for their younger brother or sister. DeFrain ${ }^{6}$ recorded the stories of Joseph and his younger sister, Mary, both adults recalling the death of their sister to stillbirth 26 years earlier. Joseph says: 'I remember picking up on the emotions from people around us ... we couldn't play, laugh, or run around ... I remember the feeling'. Mary, who was aged five years at the time, also recalls:

They told me that if I was good they would bring my little sister to the house so I could see her. I tried to be good but I only got to see her for a little while, then they took her away to the cemetery. I thought I'd get to keep my little sister. I cried at the cemetery ... I was scared. ${ }^{6}$

It is important for relatives and communities to provide frequent support and aid to families with surviving children. They 
are profoundly affected by the death of a baby brother or sister and the effects of that death on parents - and often their emotional needs go unmet.

Very young children, usually aged less than two years, may not understand anything more than that their routine has been changed, or they may observe the distress of parents. Preschoolers are more likely to comprehend the loss, but they may be unable to express their emotions verbally. Behavioral changes are not uncommon, and their distress may manifest in excessive clinginess, nocturnal fears, and tantrums. Adolescents may have both emotional reactions (which they may or may not share with others) and somatic reactions. Some withdraw from family, seeking solace in their peers. Others may experience role reversal, a process known as 'parentification'. Most children should be offered an opportunity to participate in death and remembrance rituals alongside their parents. ${ }^{6,16}$

\subsection{Subsequent children}

For many parents, though not all, the time comes when they consider having another child after their baby's death, and, unquestionably, fear plays a role in this decision. ${ }^{6}$ As in any circumstance involving trauma, when the person returns to the place or state in which the original trauma occurred, there is likely to be some degree of physical, emotional, and psychological distress. There is much conflict in the literature about attachment disorders after perinatal loss, with some studies suggesting that subsequent pregnancies after stillbirth result in maladaptive attachment. ${ }^{18}$ However, exogenous factors such as social support, unacknowledged grief, experiential avoidance, and delayed mourning can also influence outcomes in maternal attachment to a subsequent baby. Women experiencing a pregnancy after stillbirth want to continue to remember the baby who died against a backdrop of pressure to abbreviate their mourning., 2,12,16

During a subsequent pregnancy, some expectant mothers report lower levels of despair and difficulty coping, although their reported grief intensity remains high. Immediate conception after stillbirth may interrupt the mourning process and some researchers suspect that this may be the catalyst for attachment problems. ${ }^{31,32}$ Various syndromes related to attachment problems have been proposed, such as the 'vulnerable child syndrome' (characteristic of overprotective parents) and 'replacement child syndrome'; however, these are based primarily on clinical observations and lack current empirical support. ${ }^{32}$

Some research suggests that a subsequent pregnancy, timed well, may have a restorative effect on mothers. It may also be the case that women with initially lower grief intensity were more ready to attempt a new pregnancy. However, subsequent pregnancies do not appear to restore a father's perception of self in the same way it does for a mother, perhaps because of her physical entanglement and identification with the unborn baby. ${ }^{32}$

\section{Effects on professionals}

Suffering is an existential and inevitable part of the human experience. Healthcare providers often deal directly with the problem of human suffering, yet traditional pedagogical models endorse two contrasting views. One mode is to 'respond to suffering with objectivity and detachment', for the explicit purpose of maintaining objectivity and detachment. The opposing thought is that providers should 'form bonds of compassionate solidarity with [patients]. ${ }^{33}$ Compassion, from the Latin root com meaning together and pati to suffer, is a suffering together with the other and is considered by some to be a virtue in medical care, alleviating emotional angst. ${ }^{33,34}$
However, the death of a patient can incite high levels of distress in medical providers. 'Compassion fatigue' and 'vicarious traumatization' are not uncommon experiences for providers, particularly when faced with sudden and traumatic deaths such as infant and child deaths, homicide, and suicide. Providers who frequently encounter traumatic deaths are vulnerable to depressive and anxious symptoms, anger, helplessness, ${ }^{33,34}$ lethargy, intrusive thoughts, and nightmares. ${ }^{35}$ But the effects do not stop there: providers who report such symptoms may have difficulty expressing empathy, communicating with patients, and may become more avoidant and distant. These types of relational interactions diminish both patient and provider satisfaction. ${ }^{35}$

There is a growing body of scientific literature on the efficacy of mindfulness-based interventions in treating anxiety, depression, and other biopsychosocial maladies. ${ }^{36,37}$ One randomized controlled trial on mindfulness-based stress reduction with medical students resulted in a significant reduction in anxiety and depression and a remarkable increase in empathy compared to a control group. ${ }^{37}$ Mindfulness reduces the incidence of provider burn-out, self-criticism, avoidance behaviors, and improves life satisfaction and self-compassion. ${ }^{37}$ Kabat-Zinn ${ }^{38}$ defines mindfulness as the process of deep awareness, non-judgmentally in the present moment and with full acceptance. Mindfulness helps physicians 'work with the universal vulnerabilities' and the suffering that inevitable in the human experience. ${ }^{39,40}$ Mindful providers are more self-aware and engage in self-care strategies more often, a foundational aspect of the ATTEND model. ${ }^{40}$

Mindfulness interventions are gaining empirical esteem, now recognized by leading authorities in medicine and clinical practice such as the UK's National Institute of Health and Clinical Excellence. ${ }^{41}$ Deep self-awareness seems to provide a means through which providers can form healing therapeutic alliances when faced with the inevitable experience of a patient's death because they are able to better tolerate intense, emotional experiences, suffer compassion fatigue less often, are more willing to approach and deal with their own painful emotions, and are more empathic with patients and coworkers. ${ }^{33,34,37,39,41,42}$

Mindfulness training targeted toward physicians mitigates mood disturbances such as depression, fatigue, tension, and emotional exhaustion, concomitantly improving relationships with patients. Self-compassion, an axiom of mindfulness, improves honest self-reflection and leads to greater willingness to learn and adapt based on experiences. ${ }^{38,39}$ Here is one example of a mindfulness-centered, self-compassion inventory for providers ${ }^{40}$ :

1. Spend at least $15-30$ min daily in meditation, prayer, or quiet time, just 'being and not doing'.

2. Spend at least $20 \mathrm{~min}$ a day in mindful exercise. This can include yoga, running, walking, hiking; and co-attunement through barefoot nature walks can be a helpful 'in-themoment' practice.

3. Consider taking a few minutes between patients, when possible. ${ }^{12}$ Find a quiet place, close your eyes, and focus on deep, slowing breathing for several minutes.

4. Surround yourself with caring others - family, friends, and work colleagues.

5. Notice nature. Listen to the sounds of birds. Pay attention to the trees, really smell the flowers, and observe ants as they work. Just pay attention to life as it happens.

6 . Focus on daily gratitude for those things many often take for granted such as good health, family, running water, a home, and food.

7. Show compassion, actively, toward others. Volunteer at least one day per month. 
8. Express your love and affection for your partner, children, friends, and/or family. Tell others, daily, how much they mean to you.

9. Give yourself permission to experience self-compassion and self-love. Practice forgiveness, even to yourself. Find creative expression through venues such as music, art, gardening, sculpting, or poetry.

10. Take a class on death education. While it may seem macabre at first, the opportunity to explore various aspects on death and dying actually expands provider confidence and helps make life bigger, not smaller.

Provider self-care and compassion that arise from mindfulness practices may help to cultivate a more richly therapeutic environment in which both providers and patients flourish because the relationship to both self and other is the cornerstone. This model provides the framework for enhanced well-being, both personally and professionally.

Finally, providers can use mindfulness practices to become more open-hearted, openly supporting one another and sharing the stress of coping with stillbirth and other traumatic events. This may help to relieve some of the stress and existential loneliness so prevalent in working with traumatic grief..$^{14,26}$

\section{Conclusion}

The death of a child at any age and from any cause is, indeed, a life-changing, traumatic experience. Reconciliation evolves slowly and painfully for many parents as they find their way through not only the raw grief, but also the many other factors, such as historicity of loss, social support, and psychosocial care, associated with traumatic loss. The death of a baby to stillbirth has profound effects on mothers and fathers, siblings, and providers. Though this loss is often disenfranchised, mounting evidence suggests that its effects are just as impactful as any child's death, and certainly worthy of the same societal recognition.

Whereas best practice guidelines vary based in context, seeing and holding the stillborn baby seem to be associated with fewer symptoms of anxiety and depression, though this beneficial effect may be temporarily reversed during a subsequent pregnancy. ${ }^{17}$ This may be because the woman is currently facing the circumstances in which the original trauma occurred: pregnancy and childbirth. The appropriate response, therefore, is to offer these mothers additional support during a subsequent pregnancy rather than to suggest they relinquish their right to choose contact with their stillborn babies. The mother of a stillborn baby needs sensitive guidance to alleviate natural fears around meeting and saying farewell to her baby. There is no way for a mother to prepare for a tragedy like this. The onus of responsibility during these circumstances falls on providers. Active management that includes a mindful presence, responsiveness, support, and a staff willing to facilitate and normalize contact with a stillborn baby is most likely to provide long-term benefits to the mother, helping minimize the negative immediate and long-term risks of traumatic grief.

Rando ${ }^{43}$ describes traumatic death experiences as highest risk: sudden, violent, mutilating, or random; death from a lengthy illness; death of a child; the perception that it was preventable; a markedly dependent relationship; concurrent mental health problems; and death with a perceived lack of social support. She describes the grief process as consisting of six individual but interacting processes named the ' $6-\mathrm{R}$ processes':

1. Recognize the loss: acknowledge the death and understand its ramifications.
2. React to the separation of the loss, both the primary and resulting secondary losses. Experience the pain; feel, identify, accept and express the myriad emotions encompassed by the term grief.

3. Recollect and re-experience the deceased and the relationship. Review and remember realistically. Revive and re-experience all the feelings involved, including the negative aspects of the relationship.

4. Relinquish attachments to the former assumptive world.

5. Readjust to move adaptively into the new world without forgetting the deceased.

6. Reinvest the freed-up energy in a new life or identity.

In the case of stillbirth, recognition from within the family and outside the family is crucial. The sense that the baby's life is not of value implies that the mother herself lacks value. Hiding the event exacerbates shame responses. Families also, according to Rando, need to recognize the magnitude of their own losses, though no one should be coerced into confronting or re-experiencing painful or traumatic memories unwillingly. Reacting to the separation will incite deep pain, sadness, and other symptoms of distress including intense yearning for the child who died. This is the nature of grief. Recollection is a process of habituation, accommodating painful memories and learning to trust oneself in the midst of profound affective states. Relinquishing attachment to assumptions come slowly for most. This type of radical acceptance does not mean feeling neutral about the baby's death or actively accepting the death as normal. Rather, it is a gradual relinquishing of assumptions about what is fair and not fair, a surrendering to reality of loss. Readjustment also comes slowly over time and does not require parents to forget the baby who died. Reinvestment may come when parents feel ready to welcome a new child or feel better adjusted to their loss. Nevertheless, parents often express a strong desire to maintain connection to the child who died, and they are able to do so, individually and with family, through ongoing ritual, particularly when these approaching behaviors have been modeled and normalized early on by healthcare providers. ${ }^{16}$

Even when bereaved parents have good social support and a roadmap to the experience of loss, being a bereaved parent is insufferably painful. The death of a baby to stillbirth is the ultimate paradox: the convergence of life and death and the fundamental contradiction it represents. However, with proper care and compassion, families stand a better chance in the face of such indescribable loss and they need not suffer alone.

\section{Practice points}

- It is important to remember that historically stillbirths are a disenfranchised loss lacking societal recognition. This can have profound psychological effects on a mother, so early active recognition of her motherhood and the baby's worth is crucial.

- Mothers want provider sympathy, understanding, and psychoeducation. They want to know what their options are for spending time with their babies.

- Providers should proactively engage in open dialogue with the mother and her family regarding rituals such as holding, seeing, taking photographs, and other mementos of their time with the baby who died, normalizing such acts without coercion.

- Because mothers' feelings of isolation can endure for years, providers should have some type of postvention, or follow-up, system. Checking in with a mother and her family in the weeks following the baby's death and even sending a remembrance card on the anniversary of the child's death may have significant meaning. 
- Because of the high risk of shame and guilt often associated with stillbirth, providers should make referrals to local parental support groups which may help normalize parents' feelings. Referral to a counselor trained specifically in perinatal death may also be helpful for individuals, dyadic partnerships, and surviving children.

- An early counseling program which allows women to express their emotions and retell their stories of loss may help provide some benefit.

- Mindfulness-based techniques such as ATTEND foster deeper self-awareness and provide a framework through which physicians, nurses, social workers, and other professionals may be able to approach painful experiences with the traumatic deaths of patients rather than to avoid them.

- Children are often the forgotten grievers. They do mourn for their younger siblings who died, and should be actively included in rituals to whatever degree they and the informed family are comfortable.

- Subsequent pregnancies may present a temporary increase in maternal symptoms. Extra support and follow-up is warranted during this period.

- Providers using a mindfulness-based model can improve their tolerance for adverse and traumatic events through self-care and compassion. The ATTEND model emphasizes provider self-care to alleviate the risk of emotional exhaustion, existential loneliness, provider guilt, and secondary trauma.

\section{Research directions}

- More randomized trials on acute and post-loss interventions.

- Studies on same-sex couples experiencing perinatal death.

- Research on the economic gains to healthcare facilities that employ intervention strategies.

- More rigorous research on effective mental health care in women and families experiencing stillbirth.

- More research on stress-reduction techniques to alleviate the risk of secondary trauma in providers.

\section{Conflict of interest statement}

None declared.

\section{Funding sources}

None.

\section{References}

1. Davids R. Psalms of the early Buddhists, LI Văsitthī. Cantos LI. Pali Text Society. Oxford: Oxford University Press, http://digital.library.upenn.edu/women/ davids/psalms/psalms.html; 1909.

2. Froen JF, Cacciatore J, McClure E, et al. Stillbirths: why they matter. Lancet 2011;377:1353-66.

3. Barr P, Cacciatore J. Problematic emotions and maternal grief. Omega 20072008;56:331-48

4. Kersting A, Kroker K, Schlict S, Baust K, Wagner B. Efficacy of cognitive behavioral internet-based therapy in parents after the loss of a child during pregnancy: pilot data from a randomized controlled trial. Archs Women's Ment Health 2006;14:465-77.
5. Engelhard I, van den Hout M, Schouten E. Neuroticism and low educational level predict the risk of post traumatic stress disorder in women after miscarriage and stillbirth. Gen Hosp Psychiatry 2006;7:414-7.

6. DeFrain J, Martens L, Stork J, Stork W. The psychological effects of a stillbirth on surviving family members. Omega 1990;22:81-108.

7. Doka K. Disenfranchised grief: recognizing hidden sorrow. Lexington, MA: Lexington Books; 1989.

8. Doka K. Living with life-threatening illness: a guide for individuals, families, and caregivers. Lexington, MA: Lexington Books; 1993.

9. Lovell A. Some questions of identity: late miscarriage, stillbirth, and perinatal loss. Social Sci Med 1983;17:755-61.

10. Rowe-Murray HJ, Fisher J. Operative intervention in delivery is associated with compromised early mother-infant interaction. Br J Obstet Gynaecol 2001;108 1068-75.

11. Radestad I, Steineck G, Nordin C, Sjögren B. Psychological complications after stillbirth - influence of memories and immediate management: population based study. Br Med J 1996;312:1505-8.

12. Cacciatore $\mathrm{J}$. The unique experiences of women and their families after the death of a baby. Soc Work Healthc 2010;49:134-48.

13. Trulsson O, Radestad I. The silent child - mothers' experiences before, during and after stillbirth. Birth 2004;31:189-95.

14. Cacciatore J. Psychosocial care. In: Spong C, editor. Stillbirth: prediction prevention, and management. Hoboken, NJ: Wiley-Blackwell; 2011. p. 203-28.

15. Cacciatore J, Flint M. Mediating grief: postmortem ritual after a child's death. J Loss Trauma 2012;17:158-72.

16. Cacciatore J, Radestad I, Froen JF. Effects of contact with stillborn babies on maternal anxiety and depression. Birth 2008;35:313-20.

17. Hughes P, Turton P, Hopper E, et al. Disorganized attachment behavior among infants born subsequent to stillbirth. J Child Psychol 2001;42:791-801.

18. Condon J. Management of established pathological grief reaction after stillbirth. Am J Psychiatry 1986;143:987-92.

19. Hutti M. Social and professional support needs of families after perinatal loss. J Obstet Gynecol Neonat Nurs 2005;34:630-8.

20. Vance J, Boyle F, Najman J, Thearle M. Couple distress after sudden infant or perinatal death: a 30-month follow up. J Paediatr Child Health 2002:38:368-72.

21. Barr P. Guilt- and shame-proneness and the grief of perinatal bereavement Psychol Psychother: Theory Res Pract 2004;77:493-510.

22. Harper M, O'Connor R, O'Carroll R. Increased mortality in parents bereaved in the first year of their child's life. BMJ Support Palliat Care 2011;1:306-9.

23. Calderon-Margalit R, Friedlander Y, Yanetz R, et al. Late stillbirths and longterm mortality of mothers. Obstet Gynecol 2007;109:1301-8.

24. Shreffler K, Hill T, Cacciatore J. The impact of infertility, miscarriage, stillbirth, and child death on marital dissolution. J Divorce Remarriage 2012;53:91-107.

25. Lichtenthal W, Currier J, Neimeyer R, Keesee N. Sense and significance: a mixed methods examination of meaning making after the loss of one's child. J Clin Psychol 2010;66:791-812.

26. Davis D, Stewart M, Harmon R. Perinatal loss: providing emotional support for bereaved parents. Birth 1988;15:242-6.

27. Engler A, Lasker J. Predictors of maternal grief in the year after newborn death. Illness, Crisis and Loss 2000;8:227-43.

28. Lavender T, Walkinshaw S. Can midwives reduce postpartum psychological morbidity? A randomized trial. Birth 1998;25:215-9.

29. Gamble J, Creedy D, Moyle W, Webster J, McAllister M, Dickson P. Effectiveness of a counseling intervention after traumatic childbirth: a randomized controlled trial. Birth 2005;32:11-9.

30. Fletcher P. Experiences in family bereavement. Fam Commun Health 2002;1 $57-70$

31. O'Leary J. Grief and its impact on prenatal attachment in the subsequent pregnancy. Archs Women's Mental Health 2004;7:7-18.

32. Franche R, Bulow $C$. The impact of a subsequent pregnancy on grief and emotional adjustment following a perinatal loss. Infant Ment Health J 1999;20: 175-87.

33. Coulehan J. Compassionate solidarity: suffering, poetry, and medicine. Perspect Biol Med 2009;52:585-603.

34. West CP, Tan AD, Habermann TM, Sloan JA, Shanafelt TD. Association of resident fatigue and distress with perceived medical errors. JAMA 2009;302:1294-300.

35. Halbesleben J, Rathert C. Linking physician burnout and patient outcomes. Health Care Mngmnt Rev 2008;33:29-39.

36. Kabat-Zinn J. An outpatient program in behavioral medicine for chronic pain patients based on the practice of mindfulness meditation: theoretical considerations and preliminary results. Gen Hosp Psychiatry 1982;4:33-47.

37. Shapiro S, Schwartz G, Bonner G. Effects of mindfulness stress reduction on medical and premedical students. J Behav Med 1998;21:581-98.

38. Kabat-Zinn J. Full catastrophe living: using the wisdom of your mind to face stress, pain and illness. New York: Dell Publishing; 1990.

39. Crane R. Mindfulness-based cognitive therapy. New York: Routledge; 2009.

40. Cacciatore J, Flint M. ATTEND: a mindfulness-based bereavement care model. Death Stud 2012;31:61-82.

41. Segal Z, Williams J, Teasdale J. Mindfulness-based cognitive therapy for depression: a new approach for preventing relapse. New York: Guilford Press; 2002.

42. Krasner M, Epstein R, Beckman H, et al. Association of an education program in mindful communication with burnout, empathy, and attitudes among primary care physicians. JAMA 2009;302:1284-93.

43. Rando T. The increasing prevalence of complicated mourning. Omega 1992;174:43-59. 